\title{
CONCEPÇÕES DE MATEMÁTICA QUE FORJAM O ENSINO MÉDIO PROGRAMA NOVA EJA
}

\author{
Eliane Lopes Werneck de Andradel \\ Maria Cecilia de Castello Branco Fantinato2
}

\section{RESUMO}

Este artigo apresenta parte dos resultados de uma dissertação de mestrado, defendida em 2016, na qual, buscou-se discutir como são vivenciados os processos de aprendizagem em matemática no Ensino Médio no Programa NOVA EJA. O contexto em que esses processos se dão é a politica pública, de aceleração e aprendizagem, denominada NOVA EJA, implementada no Rio de Janeiro desde 2013. Para isso, pesquisamos se e como a metodologia do programa promove a valorização de saberes matemáticos experienciais, advindos das práticas sociais dos alunos. O objetivo deste artigo é analisar as concepções de matemática que permeiam o material digital do programa. Estudos teóricos em Educação e Educação Matemática fundamentaram a pesquisa qualitativa, que ampliou, nosso olhar sobre os discursos contidos nos documentos oficiais e nas políticas educacionais, direcionadas às pessoas jovens e adultas. Também foram realizadas observações em aulas de Matemática deste programa, em uma escola estadual, assim como entrevistas com cinco alunos. A análise dos dados permitiu deduzir que a concepção que perpassa o método de ensino oferecido, inclusive, no material disponibilizado aos docentes e discentes, pode levar os professores a pensar os alunos do programa de modo infantilizado e como sujeitos marginalizados das próprias práticas sociais.

Palavras-chave: EJA. Educação Matemática. Política educacional.

\section{MATHEMATICAL CONCEPTIONS THAT FORGE THE ENSINO MÉDIO PROGRAMA NOVA EJA}

\begin{abstract}
This article presents part of the results of a master's thesis, defended in 2016, in which, we sought to discuss how the processes of learning in mathematics in High School in the NOVA EJA Program are experienced. The context in which these processes take place is the public policy of acceleration and learning, called NOVA EJA, implemented in Rio de Janeiro since 2013. For this reason, we investigated if and how the methodology of the program promotes the valorization of experiential

\footnotetext{
1 Mestre em Educação (UFF). Docente I da SEEDUC RJ. E-mail: eliane.lopes.mat@gmail.com

2 Doutora em Educação (USP). Professora da Faculdade de Educação da UFF. E-mail: mcfantinato@gmail.com
} 
mathematical knowledge, from students' social practices. The purpose of this article is to analyze the conceptions of mathematics that permeate the digital material of the program. Theoretical studies in Education and Mathematics Education are the basis for our qualitative research, which broadened our focus on the discourses contained in official documents and in the educational policies directed to young people and adults. Observations were also made in Mathematics classes of this program, in a state school, as well as interviews with five students. The analysis of the data allowed us to deduce that the conception that passes through the teaching method offered, including the material made available to teachers and students can lead the teachers to think about the students of the program in an infantilized way and as marginal subjects of their own social practices.

Keywords: Adult Education. Mathematical Education. Educational Politics.

\section{CONCEPCIONES MATEMÁTICAS QUE FORJAN EL ENSINO MÉDIO PROGRAMA NOVA EJA}

\section{RESUMEN}

Este artículo presenta parte de los resultados de una tesis de maestría, defendida em 2016, en la que se trató de discutir cómo se experimentan los procesos de aprendizaje en matemáticas en la Escuela Secundaria del Programa NOVA EJA. El contexto en el que se desarrolan estos procesos es la política pública de aceleración y aprendizaje, llamada NOVA EJA, implementada en Río de Janeiro desde 2013. Para ello, investigamos si y cómo la metodología del programa promueve la valorización del conocimiento matemático experiencial, de las prácticas sociales de los estudiantes. El propósito de este artículo es analizar las concepciones de la matemática que permean el material digital del programa. Los estúdios teóricos en Educación y Matemática Educación fundamentaron la investigación cualitativa, que amplió nuestra visión de los discursos contenidos en los documentos oficiales y las políticas educativas dirigidas a jóvenes y adultos. También se realizaron observaciones en las clases de Matemáticas de este programa, en uma escuela estatal, así como entrevistas con cinco estudiantes. El análisis de los datos permitió deducir que la concepción que pasa por el método de enseñanza ofrecido, incluyendo el material puesto a disposición de profesores y estudiantes, puede conducir a los profesores a pensar los estudiantes del programa de manera infantilizada y marginal Sujetos de las prácticas sociales propias.

Palabras clave: Educación de adultos. Educación Matemática. La política educativa.

\section{INTRODUÇÃO}

O presente texto é um recorte de pesquisa de mestrado finalizada em 2016, desenvolvida pela primeira autora e orientada pela segunda. 0 quadro apresentado aborda a proposta metodológica contida no material 
digital e impresso, direcionado aos alunos e professores de Matemática do Programa NOVA EJA33 (Ensino Médio Programa NOVA EJA).

Este programa está implantado no Estado do Rio de Janeiro (RJ) desde 2013.

A origem do interesse e o encontro com o Programa NOVA EJA surgiram pelo fato de a primeira autora ser professora da rede estadual do RJ e assistir, cotidianamente, aos problemas que as políticas de aceleração de aprendizagem têm gerado na formação educacional dos alunos das escolas públicas.

Esta experiência levou à consciência da necessidade de aprofundamento de conhecimentos sobre os propósitos institucionais e pedagógicos dos locais de destino que têm sido dados aos alunos adolescentes, que apresentam comportamentos indisciplinados ${ }^{4}$, ou que estão, de acordo com a visão da Secretaria de Estado de Educação do Rio de Janeiro (SEEDUC RJ), em condição de distorção idade/série, em comparação a outros alunos de mesma faixa etária.

A confluência das experiências e aprendizados oriundos da vida particular, educacional e profissional, foi ao encontro do desejo de aprofundamento das pesquisas em Educação de Jovens e Adultos (EJA). Esses aspectos motivaram, não apenas, a observação da política NOVA EJA, como também, mais especificamente, o conhecimento de como a aprendizagem em Matemática tem sido conduzida pela SEEDUC RJ.

Partindo de uma compreensão mais ampliada do que foi exposto, surgiram algumas questões de interesse para a pesquisa. São elas:

- Os saberes matemáticos experienciais dos indivíduos, advindos das práticas sociais, têm sido privilegiados no contexto da política NOVA EJA?

\footnotetext{
3 A denominação Programa NOVA EJA foi extinta no mês de junho de 2015, passando, desde então, o referido programa a ser nomeado por Ensino Médio Programa NOVA EJA (CECIERJ, 2015, p. 4).

${ }_{4}^{4}$ Designação usada entre alguns profissionais das escolas para rotular as posturas dos alunos que não se adequam às normas escolares, reforçando o ideário de culpabilização da vítima (PATTO, 1999).
} 
- As estratégias formais/informais de aprendizagem dos alunos são valorizadas na metodologia do Ensino Médio Programa NOVA EJA (Programa NOVA EJA)?

- O que pensam os alunos a respeito do estudo de Matemática na NOVA EJA?

Iniciamos este artigo apresentando, algumas considerações à luz de referenciais teóricos oriundos da Educação e Educação Matemática.

Em seguida, trazemos parte da metodologia usada na pesquisa, e por fim, algumas das discussões realizadas sobre as concepções de matemática veiculadas pelo material didático da NOVA EJA.

\section{A EJA E A EDUCAÇÃO MATEMÁTICA}

A Educação Matemática é um campo de pesquisa educacional que trata do conhecimento matemático e dos aspectos de ensino e aprendizagem relativos à disciplina de Matemática.

O desenvolvimento desse campo tem se dado no Brasil, desde o final da década de 1980. Essa reflexão é motivada pela necessidade de revisão dos modos de ensinar a Matemática nas escolas e compreensão das práticas sociais, tanto pelo próprio caráter epistemológico da disciplina, quanto pela insatisfação da sociedade, dos professores e dos alunos com as limitações enfrentadas no ensino escolar. Tais aspectos foram os principais condicionantes para uma efetiva mudança nos modos de compreender e pesquisar o ensino e na aprendizagem em Matemática.

Para que a dimensão do direito à educação, em especial do público da EJA, seja valorizada pelos professores de Matemática, é necessário que estes tenham ciência das discussões realizadas sobre a dimensão política dos saberes curriculares 5 .

5 Para Tardif (2005) esses saberes compõem uma das quatro categoriais de saberes docentes: saberes da formação profissional, saberes disciplinares, saberes curriculares e saberes experienciais (SANTOS, 2010, p. 158). 
É importante perceber que a compreensão do papel do currículo na formação dos alunos interfere nas escolhas dos conhecimentos que serão trabalhados dentro e fora da sala de aula, conforme vários autores já destacaram (ALVISI \& MONTEIRO, 2010; DE VARGAS \& FANTINATO, 2011; EUGÊNIO, 2005).

Dessa forma, reiteramos a importância das pesquisas inseridas no campo da Educação Matemática, entendendo o mesmo como uma arena de lutas contra as desigualdades, tal como o é a EJA.

Os objetivos da investigaçãob em Educação Matemática e os estudos ou linhas de pesquisas ${ }^{7}$ deste campo de pesquisa, destacados no texto de Soares (2008), primam pela busca de caminhos, que possam nos oferecer "uma melhor compreensão dos problemas do ensino-aprendizagem em todos os níveis da Matemática" (SOARES, 2008, p. 33). E, dessa forma, "também dizem respeito a propostas de metodologias e ações que possam promover o aprendizado de formas cada vez mais eficientes" (SOARES, 2008, p. 33).

Esses estudos estão em consonância com o clamor de parte da sociedade incomodada com os baixos índices de compreensão de conteúdos matemáticos escolares. Apesar dos muitos avanços alcançados nas últimas décadas, até hoje, se discute intensamente como esses conteúdos devem ser trabalhados na escola pública básica, de modo que se garanta a melhoria da aprendizagem.

Autores, como Ventura (2011), contribuem para refletir acerca dos aspectos políticos envolvidos na modalidade EJA, que também se relacionam com a Educação Matemática. No texto, a autora destaca que,

\footnotetext{
6 Para Fiorentini \& Lorenzato (2006) esses objetivos são de natureza pragmática, que busca a melhora da qualidade do ensino e da aprendizagem da Matemática; e de natureza científica, que procura fortalecer "a Educação Matemática enquanto campo de investigação e produção de conhecimentos" (SOARES, 2008, p. 32).

7 Processos de ensino/aprendizagem de Matemática; Mudanças curriculares; Emprego de novas tecnologias no ensino de Matemática; Prática docente; Desenvolvimento profissional (de professores); Práticas de avaliação; Contexto sócio-cultural e político do ensino/aprendizagem de Matemática (KILPATRICK,1994).
} 
desde 2003, a educação voltada para o trabalhador tem assumido uma configuração ainda mais complexa. Ela afirma que, para além da histórica negação do acesso à educação, identifica-se, atualmente, a oferta de variadas formas de educação, destinadas a diferentes parcelas da classe trabalhadora.

Esse quadro, além de dar novo contorno "à problemática educacional, imprime um conteúdo e uma forma específica de regulação da educação e expressa mecanismos novos de controle social das diferentes frações da classe trabalhadora" (VENTURA, 2011, p. 83).

Para essa pesquisadora, tal cenário concorre para uma nova pedagogia da hegemonia, que propaga junto aos trabalhadores uma noção equivocada de educação, àquela que "deve preparar os indivíduos para fazerem escolhas individuais adequadas e para o desempenho pessoal eficiente, dotando-os de capacidade de competir e, por si mesmo, melhorarem suas vidas" (VENTURA, 2011, p. 84). Partindo dessa ótica, entende-se que programas, como o Ensino Médio Programa NOVA EJA, podem servir como exemplos da regulação da educação e dos mecanismos novos de controle social das diferentes frações da classe trabalhadora, na Rede Pública Estadual de Ensino do RJ.

Investido dessa perspectiva de regulação da educação e controle social, em 2011, após resultados insatisfatórios obtidos no Índice de Desenvolvimento da Educação Básica (IDEB), o governo do Estado do RJ achou "necessário lançar um olhar diferenciado sobre as diretrizes da" SEEDUC RJ (SEEDUC RJ, 2012, apresentação). Nesse documento é possível perceber como os sujeitos da rede pública têm enfrentado situações adversas nos últimos anos, e que o resultado desfavorável do IDEB, em ano eleitoral, provocou o incremento de programas e ações que tinham, sob a nossa ótica, a intenção de promover soluções de curto prazo. 


\section{O PROGRAMA NOVA EJA}

Em 2013, o Programa NOVA EJA é apresentado por seus idealizadores8 como uma nova política de Educação de Jovens e Adultos, que possui "metodologia e currículo específicos, material didático próprio, recursos multimídia e aulas dinâmicas e métodos para serem trabalhados com alunos com defasagem idade/série" (CECIERJ, s.d., perguntas frequentes, Grifo nosso). As aulas semanais presenciais têm duração de três horas e vinte minutos. E a carga horária diária, de todas as disciplinas, conforme argumentação da fundação, foi reduzida para se adequar às necessidades 9 do público de EJA.

A formação dos professores, realizada pela Fundação CECIERJ, foi oferecida, inicialmente em 2013, a todos os docentes da Rede Estadual. Para os professores que trabalhavam efetivamente com a EJA, a Formação Continuada era realizada em serviço, pela Plataforma Moodle, e em alguns encontros presenciais para todos os professores, que atuavam em turmas da NOVA EJA.

Para Estevam e Puggian (2013), esse tipo de formação oferecida aos professores "chama atenção por requerer dos docentes novas "habilidades e competências', exigindo por parte dos mesmos conhecimentos específicos da Plataforma Moodle [...]". Oferecendo a possibilidade dos alunos contarem "com professores no sistema presencial e tutores no âmbito virtual" (p. 217-218).

Como a Plataforma Moodle é o ambiente educacional virtual usado pela Fundação CECIERJ para a promoção de seus cursos à distância e semipresenciais, tal como os cursos de graduação que são oferecidos pelo

\footnotetext{
8 A SEEDUC RJ em parceria com a Fundação Centro de Ciências e Educação Superior à Distância do Estado do Rio de Janeiro (CECIERJ).

${ }^{9}$ Não encontramos nem no Manual de Orientações do Programa Nova EJA (CECIERJ, 2015), e nem em quaisquer outros documentos pesquisados, veiculados pela SEEDUC RJ ou pela Fundação CECIERJ, informações sobre quais são os tipos de "necessidades" sugeridas no texto.
} 
Consórcio CEDERJ10, torna-se importante apontar, no texto dissertativo, duas questões que se imbricam, apesar de não serem parte constitutiva do nosso objeto de pesquisa. São elas: Se a formação continuada em serviço dos professores direciona a profissionalização desses profissionais à condição de "tutores presenciais"? E com qual intenção a Tecnologia de Informação e Comunicação (TIC) é utilizada pela SEEDUC RJ?

Além disso, no período do estudo exploratório, identificamos que a aproximação da Fundação CECIERJ com programas relacionados ao público da EJA revela o fomento do governo estadual do RJ em promover, dentro de sua esfera de ação, programas à distância para atender os jovens, adultos ou idosos, que ainda não cursaram o Ensino Básico.

Portanto, a conformação do Programa NOVA EJA (Ensino Médio Programa NOVA EJA), descrita pela SEEDUC RJ, remonta a outra questão relevante e inerente aos estudos, referentes à EJA: o Programa NOVA EJA (Ensino Médio Programa NOVA EJA) está alinhado com a proposta de ensino regular (EJA) ou ao modelo de ensino supletivo?

\section{O PERCURSO METODOLÓGICO}

A metodologia adotada no presente estudo é pautada nos pressupostos da pesquisa qualitativa, que requer método rigoroso e subjetivo. Para isto, foram utilizados alguns procedimentos inerentes a este tipo de investigação, tendo como meta compreender e interpretar dados e discursos.

Como o objeto deste estudo se refere aos processos de construção de aprendizagem em matemática, vivenciados pelos alunos, em uma turma do Programa NOVA EJA, buscamos indícios de estratégias formais / informais de aprendizagem dos alunos. A análise, também, investiga se e como a metodologia do programa contribui para a valorização de saberes matemáticos experienciais, advindos das práticas sociais dos alunos.

\footnotetext{
10 Fundação Centro de Educação à Distância do Estado do Rio de Janeiro (CEDERJ).
} 
Os procedimentos foram usados a partir da pesquisa exploratória, que pôde ser realizada por intermédio de um

"[...] estudo prévio da realidade, na fase de planejamento da pesquisa, com a finalidade principal de elaborar um instrumento baseado nas experiências reais dos sujeitos, no seu vocabulário e ambiente de vida" (PIOVESAN; TEMPORINI, 1995, p. 319).

O trabalho com esse tipo de pesquisa foi estabelecendo os desdobramentos, que surgiram ao longo do percurso. São eles: a pesquisa bibliográfica, para o aprofundamento do tema e construção do texto argumentativo; a análise documental para a identificação de expressões, concepções, índices e situações, partindo de inquietações advindas da pesquisa bibliográfica e das questões da pesquisa e, finalmente, a observação de campo e a entrevista semiestruturada, inspiradas nos princípios da pesquisa de campo, que possibilitaram o acesso ao material empírico, investigado por meio da metodologia análise de conteúdo.

A análise de conteúdo é "compreendida como um conjunto de técnicas de pesquisa cujo objetivo é a busca do sentido ou dos sentidos de um documento" (CAMPOS, 2004, p. 611). E "[...] procura conhecer aquilo que está por trás das palavras sobre as quais se debruça" (BARDIN, 1977, p. 44).

Vale ressaltar que a pesquisa exploratória além de propiciar uma visão mais ampliada dos contextos que perpassaram o trabalho, também foi elemento essencial, tanto para a reflexão sobre alguns aspectos que provocaram conflitos sempre presentes no caminho do pesquisador, quanto para guiar considerações e amadurecimento, potencializando o olhar para os sujeitos entrevistados, de forma menos caricata.

Em razão da qualidade, de possibilitar maior visão do contexto da pesquisa, e da variável de estudo, Piovesan e Temporini (1995) afirmam que a pesquisa exploratória, na vertente qualitativa, aumenta o grau de objetividade da pesquisa, "tornando-a mais consentânea com a realidade" (p. 321). Além disso, acrescentam que: 
Nesse sentido, a pesquisa exploratória leva o pesquisador, freqüentemente, à descoberta de enfoques, percepções e terminologias novas para ele, contribuindo para que, paulatinamente, seu próprio modo de pensar seja modificado [...] (PIOVESAN; TEMPORINI, 1995, p. 321).

O estudo documental foi realizado por meio de leituras críticas de leis; resoluções; pareceres; manuais (Manual de Orientações Nova EJA 2013/2015); livros impressos e virtuais dos alunos (Matemática e sua Tecnologias, módulos 1, 2, 3 e 4) e dos professores (Matemática e suas Tecnologias, módulos 1, 2, 3 e 4); dos artigos da SEEDUC RJ; dentre outros.

Gil (2002) afirma que a pesquisa documental é semelhante à pesquisa bibliográfica. "A diferença fundamental entre ambas está na natureza das fontes. Apenas cabe considerar que, [...] na pesquisa documental, as fontes são muito mais diversificadas e dispersas" (p. 45).

As reflexões, realizadas pela articulação da observação dos dados com a pesquisa bibliográfica e com o estudo de campo, possibilitaram uma melhor compreensão das atuais políticas vigentes, na esfera estadual, e da situação precária em que ainda se encontra a EJA. O estudo documental se tornou relevante pela natureza dos objetos investigados.

O trabalho de campo foi desenvolvido no primeiro semestre de 2015, quando foi feita a observação participante de uma turma da NOVA EJA, que estava no quarto módulo. Nesta ocasião, decidimos pelo uso da entrevista como o procedimento metodológico, com o objetivo de observar como os sujeitos da pesquisa compreendiam o ensino de Matemática no programa.

O grupo que concedeu as entrevistas é composto por cinco alunos, que estavam terminando o Ensino Médio naquele semestre. Todos são aqui apresentados por nomes fictícios. Elisa, Olga e Alceu, trabalhadores do mercado informal, são adultos, com idade superior a trinta e oito anos. Luara tinha dezenove anos e não trabalhava. E Marina que tinha vinte anos era vendedora. 


\section{A ANÁLISE CRÍTICA DOS DADOS}

Na primeira leitura dos manuais do Programa NOVA EJA ${ }^{11}$ (Ensino Médio Programa NOVA EJA), em abril de 2014, procuramos por indícios de uma possível valorização da experiência de vida dos alunos ao longo das coleções. Apesar de não termos encontrado esses indícios, posteriormente, optamos por reler este material, após o trabalho de campo.

No retorno à leitura, no segundo semestre de 2015, buscamos identificar qual a visão de Matemática e de aluno de EJA que o programa veicula nos textos.

Apesar de saber que a turma observada não havia acessado ao livro do quarto módulo, duas alunas entrevistadas comentaram, em seus depoimentos, que receberam módulos anteriores. Por isso, insistimos em analisar o material citado, por acreditarmos que tal análise constituía-se como mais um elemento importante para observarmos qual é a concepção do direito à educação, de qualidade, assumida pelo governo, para os alunos da EJA.

Ao realizarmos a releitura dos manuais, percebemos inicialmente uma tendência a privilegiar uma visão utilitarista e simplória da Matemática, sobretudo nos exemplares referentes ao primeiro módulo (do aluno e do professor).

Tal percepção nos fez ampliar a ideia de concepção infantilizadora ${ }^{2}$, para que ela abarcasse, também, as práticas e concepções de ensino de Matemática que são oferecidas aos adolescentes do Ensino Fundamental diurno, tanto nas aulas, como nos materiais destinados a eles na rede pública.

\footnotetext{
11 Os exemplares dos alunos e dos professores são encontrados na forma digital (no site do programa) ou na forma impressa.

12 A perspectiva assistencialista e infantilizadora da EJA, segundo Ribeiro, são fatores que prejudicam "a constituição do campo, limitando as condições de se ofertar aos educadores uma formação adequada, que considere as especificidades do público dessa modalidade educativa" (RIBEIRO, 1999, p. 188-189).
} 
$\mathrm{Na}$ introdução da primeira unidade, do Módulo 1 - Matemática (CECIERJ, 2013a), referente aos números inteiros e racionais, por exemplo, observam-se considerações sobre o uso de tais conjuntos em situações cotidianas bem elementares. Vejamos dois exemplos:

\begin{abstract}
Para início de conversa
Você já pensou em viver sem os números? Já experimentou passar um dia inteiro sem escrever, ver ou mencionar nenhum número? Difícil, não é mesmo? Vemos números nos extratos bancários, nos valores a pagar no supermercado, em pesquisas divulgadas a mídia, em placas de carro ou números de telefone, na nossa idade, em materiais de construção, na especificação de alguns tipos de canos ou tubos, entre muitas outras situações. Vamos ver algumas

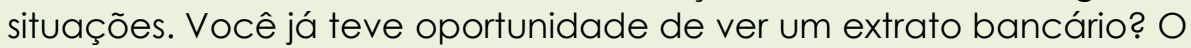
extrato bancário é o registro das atividades de entradas e saídas de valores me dinheiro em uma conta corrente [...] (CECIERJ, 2013a, p. 5).
\end{abstract}

Observe que o correntista tem uma grande movimentação em sua conta. Inicia o período com saldo de 208 Reais e recebe o pagamento de 1790 Reais. Fica então com $208+1790=1998$ Reais de saldo.

Daí por diante, é só conta a pagar: cheque, saques para os gastos do mês, fatura do cartão de crédito etc.

Um dos itens que frequentemente representam saídas de valores em contas correntes é a alimentação. Além disso, ao preparar uma receita, normalmente muitos números estão envolvidos também. Uma boa pedida para um final de semana é uma pizza... Saboroso e rápido de preparar. Vamos fazer juntos? Basta acompanhar a receita - e não se esqueça de convidar seu professor ou professora para o lanche! (CECIERJ, 2013a, p. 6).

A forma de abordagem do conteúdo parece inadequada para 0 trabalho com alunos de Ensino Médio - jovens, adultos e idosos - residentes no meio urbano, independentemente, de serem trabalhadores ou não, pois subentende que esses não conhecem um extrato bancário, ou que não sabem que a alimentação representa a maior fonte de despesa nas famílias.

Outra passagem, que mostra nosso incômodo pode ser encontrada na oitava página do módulo citado, já que faz referência à necessidade do uso dos números racionais, nas práticas desenvolvidas pela humanidade. A autora conta que as quantidades representadas por estes números referemse às medidas de volume, de capacidade e de comprimento, como se 
estivesse falando com pré-adolescentes ou adolescentes de Ensino Fundamental diurno. Vejamos o fragmento:

Há algum tempo, o homem sentiu a necessidade de utilizar números que representassem partes de um todo, como a metade de um bolo, $2,25 \mathrm{~kg}$ de batatas ou ainda um saco e 1/3 de farinha. Ao medir a altura de uma pessoa, por exemplo, dificilmente vamos encontrar medidas representadas por números inteiros. Nem todas as pessoas têm exatamente 1 metro de altura ou 2 metros de altura. Algumas pessoas têm 1,68 metros ou 1,73 metros, por exemplo. Estes números que mencionamos aqui fazem parte de dois grandes conjuntos numéricos: os números inteiros e os números racionais. Esta organização é inclusiva, ou seja, os números inteiros também são números racionais - você sabia disso? Não? Então essa é a hora de saber! Vamos lá? (CECIERJ, 2013a, p. 8).

Para explicar as operações de soma e subtração entre números inteiros, observa-se, claramente, uma postura infantilizadora, no decorrer do texto, expressa, por exemplo, da seguinte forma: "Você percebeu que o número de maior módulo sempre será o 'vencedor'" (CECIERJ, 2013a, p. 15).

Reiteramos que, comumente, este tipo de linguagem é adotada por professores que trabalham com adolescentes do Ensino Fundamental diurno. No entanto, no Ensino Médio de EJA, o público é amadurecido em vários sentidos, sendo dispensável o uso de termos como "vencedor" ou "perdedor" no trabalho com a Matemática ou com qualquer outra disciplina escolar.

Conforme alguns estudos, como os de Ribeiro (1999) e Fantinato (2003), esta infantilização pode comprometer a aprendizagem dos alunos da EJA de diversas formas, porque lhes impregna o comportamento, tornando o aprendizado ainda mais limitado, devido a um possível desencadeamento de bloqueios, que podem contribuir para a desmotivação na busca pelo conhecimento.

Outra constatação, obtida pela releitura e análise do material foi a de que a maior parte das atividades propostas para os alunos executarem não tem nenhuma referência direta aos saberes da experiência dos alunos, no intuito de incentivá-los a trazer suas próprias vivências, com conhecimentos matemáticos para o debate na sala de aula. 
Dispostas no final da seção há outras questões retiradas do Banco de Questões da Prova Brasil, Banco de Questões Saerj/Saerjinho (seis exercícios aligeirados, três deles descontextualizados, e a outra metade com características similares aos próximos exemplos) e mais quinze atividades extras, dentre as quais, somente quatro têm formato contextualizado, conforme destacamos a seguir:

\section{EXERCÍCIO 7}

Um pedreiro foi contratado para construir um muro. No primeiro dia de serviço, ele constrói um oitavo do muro e no segundo dia, o triplo do que havia construído no primeiro dia. Desta forma, nos dois primeiros dias ele já construiu:

a) menos da metade do muro;

b) o muro inteiro;

c) a metade do muro;

d) mais da metade do muro (CECIERJ, 2013a, p. 62).

\section{EXERCÍCIO 11}

A prestação da compra de uma casa é de $R \$ 4000,00$. Se houver uma correção de $35 \%$ sobre esta prestação, ela passará a ser de:

a) $R \$ 41410,00$ b) $R \$ 5140,00$ c) $R \$ 5000,00$ d) $R \$ 5400,00$ (Ibid., p. 63).

\section{EXERCÍCIO 14}

Com $20 \%$ de desconto, paguei $R \$ 64,00$ por uma capa. $O$ preço sem desconto é:

a) $R \$ 90,00$ b) $R \$ 80,00$ c) $R \$ 76,00$ d) $R \$ 66,00$.

\section{EXERCÍCIO 15}

Sobre uma dívida de $R \$ 60000,00$ obteve-se um desconto de $10 \%$. Sobre o restante, obteve-se um outro desconto que reduziu a dívida para $R \$ 43200,00$. O segundo desconto foi de:

a) $18 \%$ b) $20 \%$ c) $25 \%$ d) $28 \%$ (CECIERJ, 2013a, p. 64).

Nessa unidade, contamos um total de cinquenta e uma questões, dentre as quais, dez são contextualizadas em situações cotidianas no formato dos exemplos anteriores.

As unidades posteriores são apresentadas de forma equivalente. Também ao manusear o Módulo 4 - Matemática (CECIERJ, 2013b), observamos que o conteúdo, mesmo que fazendo parte do currículo de Ensino Médio, é apresentado praticamente da mesma forma, porém, mais incrementado em relação à incidência de maior número de passagens 
históricas, tanto para ilustrar as explicações no texto, quanto em relação às sugestões de aprofundamento de conteúdo nos sites disponibilizados.

Sob nossa ótica, esse é o aspecto de maior relevância, disponibilizado no material, pois as passagens históricas, além de contextualizarem as considerações sobre os conteúdos escolares, também problematizam algumas atividades propostas aos alunos.

A escolha de reler os exemplares do quarto módulo se deu porque a turma observada encontrava-se neste estágio do curso e, por esse motivo, tivemos curiosidade em perceber se os procedimentos do material introdutório se repetiam ali.

Refletindo sobre a importância que pode ter uma coleção como esta para a formação dos alunos e como um elemento formador de concepções de professores de Matemática de EJA, entendemos que a linguagem escrita e visual, empreendida no material observado, é muito simples para ser aplicada a alunos trabalhadores no Ensino Médio. Há ocasiões em que é apresentada de forma explicitamente infantilizada, que, sob a nossa ótica, pode, inclusive, incomodar um leitor mais atento, conforme ilustra as situações descritas abaixo.

Para tratar do conteúdo "Conjunto universo", a seguinte "situaçãoproblema" utilizada é iniciada assim: "A metade dos alunos de uma turma é composta por meninos. Se a turma possui 13 meninos, quantos são os alunos dessa turma?" (CECIERJ, 2013a, p.120).

O mesmo tipo de situação-problema é apresentado na introdução do conteúdo "Proporcionalidade e Semelhança de polígonos":

Beatriz e Estela prepararam refrescos seguindo a orientação do rótulo, mas Beatriz usou um copo com $200 \mathrm{ml}$ de capacidade e Estela usou outro com $300 \mathrm{ml}$ de capacidade. O que ocorre nesta situação? Será que os refrescos feitos pelas meninas ficaram iguais? O que você acha? Vamos analisar a situação (CECIERJ, 2013a, p. 237).

Na sequência, em relação à coleção dos professores, verificamos que os módulos que a compõem têm a seguinte formatação padrão: uma 
tabela com a Apresentação da unidade do material do aluno e uma longa seção apresentando os Recursos e ideias para o Professor, que é subdividida nas atividades organizadas. De acordo com o texto, para dar suporte às aulas, são indicados recursos, ferramentas e ideias, que são categorizadas como: atividades em grupo ou individuais; ferramentas; applets; avaliação e exercícios.

As atividades em grupo ou individuais do primeiro módulo representam uma categoria de recursos compostos por jogos em que, geralmente, são trabalhados os conteúdos matemáticos, dentre os quais, vários são apresentados de forma até mais infantilizada do que as atividades encontradas no módulo dos alunos.

$\mathrm{Na}$ dissertação, para contextualizar essas considerações, citamos, por exemplo, a proposta de uso do jogo Labirinto de inteiros e as respectivas orientações operacionais e pedagógicas (CECIERJ, 2013c, p. 8) para o trabalho, com esse tipo de recurso, em turmas de Ensino Médio na EJA.

$\mathrm{Na}$ categoria ferramentas, o procedimento inadequado se repete, fomentando, entre os professores, a ideia de que jovens, adultos e idosos da EJA devem aprender Matemática como se pensassem como alunos crianças ou adolescentes das classes diurnas do Ensino Fundamental. Em uma das atividades é recomendado o uso de um Software "Marque $V$ ou F" (CECIERJ, 2013c, p. 9), que pode ser acessado em um site direcionado ao aprendizado e treinamento de conteúdos dos anos iniciais.

Após a leitura dos exemplos citados, não causa estranheza verificar que, na categoria avaliação, o material proponha atividades descontextualizas, incentivando, principalmente, a memorização e repetição de conteúdos como forma de aprendizado, desconsiderando outras formas de aprendizagem.

Na Seção - Avaliação da Aprendizagem: Números Inteiros (CECIERJ, 2013c, p. 43), por exemplo, estão dispostas dez questões que seguem o estilo apresentado a seguir: 
Sugestões de questões objetivas para a avaliação da aprendizagem:

1. Podemos afirmar que:

a) todo número natural é inteiro.

b) todo número inteiro é natural.

c) todo número inteiro negativo é natural.

d) todo número natural é inteiro negativo (CECIERJ, 2013c, p. 44).

Sendo reforçado tal modelo em outra atividade complementar intitulada Folha de atividades - Momento de Reflexão. Na sequência, segue parte dos exercícios:

Folha de atividades - Momento de Reflexão

Questão 1: Qual foi o conteúdo matemático estudado nessa unidade?

Questão 2: Cite alguma situação do cotidiano que envolve os conhecimentos aqui estudados.

Questão 3: Copie os números da listagem abaixo, ordenando-os do maior para o menor [...]

Questão 4: Complete as afirmações abaixo:

a) Quando multiplicamos um número inteiro positivo por outro número inteiro positivo, obtemos um búmero Quando multiplicamos um número inteiro positivo por outro $\begin{array}{lrrrr}\text { b) Quando multiplicamos um número inteiro positivo por outro } \\ \text { número } & \text { inteiro } & \text { negativo, } & \text { obtemos } & \text { um }\end{array}$ número

c) Quando multiplicamos um número inteiro negativo por outro número inteiro negativo, obtemos um número

Questão 5: Para encontrar os resultados das operações: Helena usou as regras a seguir:

- Números com sinais iguais, o resultado é positivo.

- Números com sinais diferentes, o resultado é negativo.

Verifique quais resultados encontrados por Helena estão incorretos: $[\ldots]$

Quais dicas você daria à Helena para que ela não cometa mais esses erros? (CECIERJ, 2013c, p. 45 - 46).

Verifica-se que, em meio aos exemplos selecionados, observa-se somente uma referência a situações cotidianas na questão 2, que passa praticamente despercebida entre os outros exercícios aligeirados.

\section{CONCEPÇÕES DE MATEMÁTICA NO MATERIAL DA NOVA EJA}

A leitura do material digital e impresso, destinado aos alunos $\mathrm{e}$ professores do Ensino Médio Programa NOVA EJA (Programa NOVA EJA), parece indicar que a intenção de seus mentores é manter "O papel 
regulador da educação" (RUMMERT \& VENTURA, 2007) ao veicular a concepção utilitarista e simplória, implícita em tais textos.

Portanto, não concordamos com a afirmativa de Esquincalha e Pinto (2014, s.p.), onde eles defendem que o material didático do programa busca

[...] se relacionar com aspectos da vida cotidiana, adulta e profissional, enfocando situações que motivem o estudo de Matemática e que justifiquem o seu aprendizado. Apesar de usar o material elaborado para Educação a Distância, o aluno da Nova EJA estuda presencialmente.

Em Riccio (2010), encontram-se comentários sobre duas concepções distintas de utilização das Tecnologias da Informação e Comunicação (TIC). Uma delas pode fomentar a concepção de homem, concebida pela lógica do capital, "As TIC, que fazem uso da linguagem digital, são também o alicerce do processo de globalização vivido atualmente [...]" (p. 24).

Por outro lado, a outra é denominada de concepção de homem histórico-social, pois que o ciberespaço "pode ser visto como uma alternativa para combater a alienação, já que é concebido como um espaço social, e é justamente nos espaços sociais que essa alternativa de transformação se encontra" (LAPA, 2005 apud RICCIO, 2010, p. 25).

Para mostrar como a linguagem usada nos manuais dos professores também é inadequada no trato com os professores, trazemos um fragmento, referente ao Módulo I (CECIERJ, 2013c), que pode ser encontrado no início da introdução da segunda unidade.

Destacamos esse trecho, por considerar que há nele um descuido dos autores ao dialogar com os professores, que pode comprometer mais ainda a aceitação do material pelo professorado, mais atento ao conteúdo em exposição. Veja que comentar que "letras" em matemática devem ser chamadas de "variáveis", no trabalho com os alunos, pode ser interpretado como forma de desrespeito ao conhecimento matemático do professor licenciado na disciplina: 
Na unidade 2 do material do aluno, são apresentadas algumas situações que podem ser representadas e resolvidas através da álgebra. Nesta unidade, o aluno terá a oportunidade de aprender como utilizar letras (que chamaremos de variáveis) para representar diferentes valores e representar diversas situações (CECIERJ, 2013c, p. 63, Grifo nosso).

Conforme ocorre no manual oferecido aos alunos, entende-se que dialogar com estes dessa forma é compreensível, visto que o conteúdo ali proposto trata-se de uma revisão do Ensino Fundamental, e que o processo de construção de conhecimento formal, em geral, é longo e, portanto, no início do Ensino Médio, pode haver alguns alunos que não tenham conseguido atingir um grau de aprendizagem satisfatória do conhecimento destacado. Vejamos um dos trechos onde a associação é realizada:

Você pode perceber que b assume diferentes valores, ou seja, varia de acordo com a quantidade a ser comprada. Pelo fato de esta letra poder assumir diferentes valores, ela é chamada variável.

Nesta unidade, vamos aprender um pouco de Álgebra, isto é, vamos utilizar letras (que chamaremos de variáveis) para representar diferentes valores e representar diversas situações (CECIERJ, 2013a, p. $66-67)$.

No quarto módulo, direcionado aos professores a disposição das orientações, é, praticamente, a mesma que a encontrada no primeiro módulo. A primeira atividade encontrada (CECIERJ, 2013d, p. 9) é um dos poucos exemplos em que uma situação é contextualizada, sem o estigma do padrão infantilizador e aligeirado das demais.

Nessa atividade, os alunos são convidados a ler "dois textos relacionados ao tema Acréscimo de um dígito no número de celular" para, em seguida, fazer "uma correlação entre o assunto e o tema Análise Combinatória".

Nesse módulo, também há várias recomendações de atividades interativas, com necessidade de acesso frequente a computadores, além de conexão à Internet sem restrição. É limitado o uso dessas atividades em unidades escolares, em situação equivalente à unidade pesquisada, em consequência da escassez de recursos tecnológicos em funcionamento satisfatório no recinto. 
A questão que se impõe aqui não é uso deste ou daquele recurso didático, mas sim o direito do aluno a construir sua aprendizagem por meio de outros materiais, além daqueles usados nas aulas expositivas tradicionais (quadro e caneta), conforme bem observou Thees (2012). As formas de aprender são várias, muitas vezes apoiadas em diversos tipos de suportes, por isso, uma diversidade maior de materiais para o trabalho na EJA pode ser bem-vinda. Vejamos o que dizem os alunos entrevistados sobre isso.

No quarto módulo, direcionado aos professores a disposição das orientações, é, praticamente, a mesma que a encontrada no primeiro módulo. A primeira atividade encontrada (CECIERJ, 2013d, p. 9) é um dos poucos exemplos em que uma situação é contextualizada, sem o estigma do padrão infantilizador e aligeirado das demais.

Nessa atividade, os alunos são convidados a ler "dois textos relacionados ao tema Acréscimo de um dígito no número de celular" para, em seguida, fazer "uma correlação entre o assunto e o tema Análise Combinatória".

Nesse módulo, também há várias recomendações de atividades interativas, com necessidade de acesso frequente a computadores, além de conexão à Internet sem restrição. É limitado o uso dessas atividades em unidades escolares, em situação equivalente à unidade pesquisada, em consequência da escassez de recursos tecnológicos em funcionamento satisfatório no recinto.

A questão que se impõe aqui não é uso deste ou daquele recurso didático, mas sim o direito do aluno a construir sua aprendizagem por meio de outros materiais, além daqueles usados nas aulas expositivas tradicionais (quadro e caneta), conforme bem observou Thees (2012). As formas de aprender são várias, muitas vezes apoiadas em diversos tipos de suportes, por isso, uma diversidade maior de materiais para o trabalho na EJA pode ser bem-vinda. Vejamos o que dizem os alunos entrevistados sobre isso.

Para Alceu os livros se destacam: 
Hoje em dia, né, com esse negócio de Internet, né, eu creio que não entra assim muito na mente das pessoas ficarem estudando muito pela Internet, mas no livro que aquilo ali está armazenado. Eles só copiam passam pela matéria mesmo e quase não estudam por causa disso [...] (ALCEU, 08 jul. 2015).

Para Marina são as práticas lúdicas:

É às vezes facilita bastante uma música, pegar a fórmula e cantar em forma de música, que música hoje em dia a gente grava bastante. É uma forma que alguns professores adotaram [...].

Então que às vezes se torna uma coisa muito séria. E a gente às vezes acaba fugindo do assunto. Então quando se torna uma brincadeira, às vezes. Não que seja brincadeira, uma coisa séria. Mas você acaba aprendendo melhor. Você acaba memorizando melhor, assim como a gente memoriza uma música.

[...] É mais leve (MARINA, 25 jun. 2015).

E para Elisa, a relevância está nas aulas expositivas, associadas ao interesse do professor pelo aprendizado do aluno, onde o quadro/caneta-giz e o caderno são os suportes de destaque:

[...] Então a professora tem que ir sim pro quadro tem que fazer 0 exercício junto com o aluno [...] chamar um por um na mesa igual ela faz, deixa eu ver como você fez mostra o interesse que ela tem em ver como cada um tá fazendo o seu e pelo menos pra mim eu acabo me sentindo segura pra aprender aquela matéria, então tem sim muita diferença de um professor para o outro e bastante (ELISA, 11 jun. 2015).

A diversidade de sujeitos da EJA, de suas aprendizagens anteriores, de seus modos de ver o mundo e construir a própria história de vida, deve orientar práticas críticas, que busquem contemplar a pluralidade, tanto de alunos, quanto de professores, formados em velhos/novos tempos e em novos/velhos tempos. Toda esta gama de diversidades deve ser respeitada e ser objeto de discussão por alunos, professores e pesquisadores, nos espaços de sala de aula da EJA e da formação de professores.

Os vários setores dos órgãos públicos não têm mantido as unidades escolares equipadas com recursos pedagógicos de qualidade, e uma grande parte dos professores de EJA não utilizam livros ou outros materiais apropriados com suas turmas, por algumas razões apresentadas, por exemplo, na pesquisa de Thees (2012). 
Esses recursos são muito importantes para que os alunos se apropriem, com mais desenvoltura, das práticas de leitura e de escrita, tornando-se, consequentemente, menos dependentes somente dos 'resumos hiperenxutos', elaborados por professores para alunos, pensados, equivocadamente, como 'sujeitos hipersimplórios'.

Em artigo da Revista EDUCAÇÃO UOL (RIBAS, 2014, s.p.), O coordenador do programa de Educação de Jovens e Adultos da ONG Ação Educativa, Roberto Catelli13, "que trabalha na pesquisa e promoção da educação", mostra sua preocupação com o tema. Para ele "o material didático é uma das portas para garantir o direito à educação. E faz parte do direito à educação para essas pessoas ter um material adequado", afirma.

No mesmo artigo, Osmar Fávero dá destaque à importância dos livros. "O material didático é essencial para fixar a aprendizagem com jovens e adultos", diz. "Você pode trabalhar com o grupo a partir de debate, por exemplo, como Paulo Freire propunha, mas precisa criar a prática da leitura e a prática da escrita. E o material didático nesse ponto é fundamental".

\section{CONSIDERAÇÕES FINAIS}

Ao longo da pesquisa apresentada, defendemos que os alunos devem ser ouvidos durante toda a sua estada na escola, participando de discussões que digam respeito a situações que os cercam, ao que pensam das coisas do mundo e às diferenças entre as várias matemáticas que circulam em nossa sociedade, inclusive, aquelas que eles vivenciam fora da escola, nas diversas práticas sociais nas quais estão inseridos.

Os resultados da pesquisa realizada, entretanto, revelaram que os saberes experienciais dos alunos não são privilegiados nem no material do Programa e nem nas aulas de Matemática, mostrando que, em geral, a

13 "[...] também foi um dos responsáveis pela produção de um material direcionado especificamente para esse segmento, a coleção Viver, Aprender, editada pela ONG" (RIBAS, 2014, s.p.). 
prática pedagógica da escola básica continua bancária e alienada das recomendações, realizadas por pesquisadores da área da Educação.

Embora os idealizadores do material da NOVA EJA o proclamem inovador, no cômputo geral, não concordamos com tal afirmativa, pelo contrário, numa visão crítica, esse material acentua a invisibilidade dos saberes matemáticos construídos nas práticas sociais, como ocorre na escola (FANTINATO \& DE VARGAS, 2010).

A aluna Olga comentou que inventa modos para resolver problemas do dia a dia, dando como exemplo, o uso da porcentagem. Também afirmou que ela e a maior parte das pessoas, que conhece, valorizam os modos informais de resolução de problemas cotidianos. Mas os professores, em geral, não os valorizam, pois estes sempre exigem os métodos algébricos para a resolução de problemas.

Tais exemplos indicam que os alunos não começam a entender os conteúdos matemáticos, simplesmente, devido a sua contextualização (RIBEIRO, 1999; OLIVEIRA, 2004), mas que conversas no Ensino Médio, para além de experiências cotidianas simples, podem gerar maior entrosamento entre alunos e professores, promovendo laços afetivos na busca pelo conhecimento.

Além disso, a análise dos dados obtidos revelou que, tanto o material, quanto as práticas pedagógicas privilegiam as concepções de ensino de matemática aligeiradas, infantilizadoras, universalistas e utilitaristas, formando alunos dependentes de 'resumos hiperenxutos', elaborados por professores para pessoas pensadas, equivocadamente, como 'sujeitos hipersimplórios'.

Rever o que nós professores dizemos, fazemos e reproduzimos, com a devida reflexão e embasamento teórico e documental, é condição fundamental e ética para trabalharmos na educação pública, visto que nossa ingênua displicência pode ser usada contra o direito dos mais pobres à educação de qualidade e ratifica a visão paternalista, assistencialista e filantrópica que tem sido imputada à EJA. 
Estamos aqui defendendo a qualidade do material destinado à EJA, de modo a contemplar uma linguagem elaborada e simples, adequada ao Ensino Médio que atende jovens, homens e mulheres, não importando que estes sejam trabalhadores ou não, ou que façam parte de programas de aceleração.

Vimos que para Alceu, os livros se destacam; para Marina são as práticas lúdicas; Elisa ressalta aulas expositivas, associadas ao interesse do professor pelo aprendizado do aluno, e Olga renega a rigorosidade conteudista dos professores, que não se atém às necessidades dos alunos com maiores limitações de aprendizagem.

A diversidade e o desejo dos alunos de aprender os conteúdos formais, para a ampliação da compreensão de mundo e inserção em práticas sociais que necessitam do ensino formal, mostram a necessidade de materiais e métodos condizentes com as necessidades reais deles.

Tais materiais devem contribuir para a ampliação das concepções de mundo, na perspectiva freireana, das práticas de leitura e escrita mais avançadas e, consequentemente, para uma alfabetização matemática mais abrangente.

Esperamos que este trabalho tenha suscitado o interesse do leitor em aprofundar os conhecimentos e reflexões em estudos que discutam as diversas relações entre a EJA e a Educação Matemática, principalmente no que se refere à viabilização do direito constitucional, e humanizador para todas as pessoas que buscam a aprendizagem formal de conteúdos escolares, na escola básica. A partir do depoimento da aluna Olga, ao responder por que voltou a estudar, podemos intuir considerações que avancem nessa direção:

Aluna: Pra aprender mais, aproveitar o tempo perdido e aproveitar pra fazer cursos melhores que exijam o segundo grau.

Pesquisadora: O que espera da escola?

Aluna: Aprender (OLGA, 22 jun. 2015). 


\section{REFERÊNCIAS}

ALVISI, C.; MONTEIRO, A. Trânsitos entre a "Verdade" e a "Experiência": desafios curriculares na Educação de Jovens e Adultos. Horizontes, v. 28, n.1, p.33-40, jan./jun. 2010.

BARDIN, L. Análise de conteúdo.Tradução de Luís Antero Reto e Augusto Pinheiro. Edições 70, Lda. Lisboa/Portugal. 1977.

CAMPOS, C. J. G. MÉTODO DE ANÁLISE DE CONTEÚDO: ferramenta para a análise de dados qualitativos no campo da saúde. Rev Bras Enferm, Brasília (DF). 2004 set/out;57(5):611-4.

CECIERJ. Fundação Centro de Ciências e Educação Superior à Distância do Estado do Rio de Janeiro. Projeto SEEDUC. 2015. Disponível em: <http://projetoseeduc.cecierj.edu.br/eja.php>. Acesso em: 26 jul. 2015.

CECIERJ. Fundação Centro de Ciências e Educação Superior à Distância do Estado do Rio de Janeiro. EJA: perguntas frequentes. s.d. Disponível em: <http://projetoseeduc.cecierj.edu.br/eja-faq.php>. Acesso em: 26 jul. 2015.

CECIERJ. Fundação Centro de Ciências e Educação Superior à Distância do Estado do Rio de Janeiro. Matemática e suas tecnologias. Módulo 1 Matemática / Cléa Rubinstein. 2013a.

CECIERJ. Fundação Centro de Ciências e Educação Superior à Distância do Estado do Rio de Janeiro. Matemática e suas tecnologias. Módulo 4 Matemática /Rio de Janeiro. 2013b.

CECIERJ. Fundação Centro de Ciências e Educação Superior à Distância do Estado do Rio de Janeiro. Módulo I do professor. 2013c.

CECIERJ. Fundação Centro de Ciências e Educação Superior à Distância do Estado do Rio de Janeiro. Módulo IV do professor. 2013d.

DE VARGAS, S. M. \& FANTINATO, M. C. C. B. Formação de professores da educação de jovens e adultos: diversidade, diálogo, autonomia. Rev. Diálogo Educ., Curitiba, v. 11, n. 34, p. 915-931, set./dez. 2011.

ESQUINCALHA, A. C.; PINTO, G. M. F. Elaboração de Material Didático de Matemática para Professores e Alunos da Educação de Jovens e Adultos. VI EEMAT. Sociedade Brasileira de Educação matemática. Regional Rio de Janeiro. De 25 a 27 de setembro de 2014.

ESTEVAM, A.; PUGGIAN, C. Educação de Jovens e Adultos no Estado do Rio de Janeiro: Considerações sobre a reformulação curricular do ensino médio regular noturno. In: ALVES, N.; CAVACO, C.; GUIMARÃES, P.\& MARQUES, M. (Eds.), Atas do VI Seminário Luso-Brasileiro Educação, Trabalho e Movimentos Sociais - das políticas às lógicas de ação. Lisboa: IE-UL. 2013. p. 215-225.

EUGÊNIO, B. G. O Currículo na Educação de Jovens e Adultos. ANPED - GT: Educação de Jovens e Adultos / n.18 - 2005. 
FANTINATO, M. C. C. B. \& DE VARGAS, S. M. Saberes matemáticos do campo e da escola: processos de aprendizagem e educação de jovens e adultos. Quadrante, Vol. XIX, N ${ }^{\circ} 1,2010$.

FANTINATO, M. C. C. B. Identidade e Sobrevivência no Morro do São Carlos: representações quantitativas e espaciais entre jovens e adultos. 2003. São Paulo: Faculdade de Educação da USP. 198f. Tese (Doutorado em Educação). 2003.

FIORENTINI, D.; LORENZATO, S. Investigação em Educação Matemática: percursos teóricos e metodológicos. Campinas: Autores Associados, 2006.

GIL, A. C. Como elaborar projetos de pesquisa. 4ª ed. São Paulo: Atlas, 2002.

KILPATRICK, J. Investigación en Educación Matematica: Su Historia y Alguns Temas de Actualidad. In KILPATRICK, RICO \& GÓMEZ (Org.). Educación Matematica. México: Grupo Editorial Iberoamerica, 1994. p. 1-19.

LAPA, A. B. A formação crítica do sujeito na educação a distância: a contribuição de uma análise sócio-espacial. 2005. 302f. Tese (Doutorado em Planejamento Urbano e Regional) - Instituto de Pesquisa e Planejamento Urbano e Regional, Universidade Federal do Rio de Janeiro, Rio de Janeiro, 2005.

OLIVEIRA, M. K. Ciclos de vida: algumas questões sobre a psicologia do adulto. 2004.

PATTO, M. H. S. A Produção do Fracasso Escolar: histórias de submissão e rebeldia. São Paulo: Casa do Psicólogo, 1999.

PIOVESAN, A.; TEMPORINI, E. R. Pesquisa exploratória: procedimento metodológico para o estudo de fatores humanos no campo da saúde pública. Rev. Saúde Pública, 29 (4), 1995.

RIBAS, P. Revista EDUCAÇÃO UOL Ainda inadequado. Educação de jovens e adultos | Edição 205 Maio/2014.

RIBEIRO, V. R. A formação de educadores e a constituição da educação de jovens e adultos como campo pedagógico. Educação e Sociedade. Campinas, dez. 1999, vol.20, nº.68, p.184-201.

RICCIO; N. C. R. Ambientes virtuais de aprendizagem na UFBA: a autonomia como possibilidade. 2010. 363f. Tese (Doutorado em Educação) Universidade Federal da Bahia. Faculdade de Educação, Salvador, 2010.

RUMMERT, S. M. \& VENTURA, J. P. Políticas públicas para educação de jovens e adultos no Brasil: a permanente (re)construção da subalternidade considerações sobre os Programas Brasil Alfabetizado e Fazendo Escola. Educar, Curitiba, n. 29, p. 29-45, 2007. Editora UFPR.

SANTOS, J. J. R. Especificidades dos saberes para a docência na educação de pessoas jovens e adultas. Práxis educacional v.6, n.8 (pp.157-176) jan/jun 2010. 
SEEDUC RJ. Secretaria de Estado de Educação. SEEDUC em números Transparência na Educação. 2012.

SOARES, L. H. Aprendizagem significativa na educação matemática: uma proposta para a aprendizagem de geometria básica. 2008. 137f. Dissertação (Mestrado em Educação) - Universidade Federal da Paraíba 2008.

TARDIF, M. Saberes docentes e formação profissional. 5. ed. Petrópolis: Vozes, 2005.

THEES, A. Estudo com professores de matemática de jovens e adultos sobre suas práticas profissionais. 2012. 198f. Dissertação (Mestrado em Educação) Universidade Federal Fluminense, Faculdade de Educação, Rio de Janeiro, 2012.

VENTURA, J. A Trajetória Histórica da Educação de Jovens e Adultos Trabalhadores. In: TIRIBA, L. e CIAVATTA, M. (Org.). Trabalho e Educação de Jovens e Adultos. Brasília: Líber Livro e Editora UFF, 201 1. p. 57-97.

Recebido em: Março de 2017

Aceito em: Junho de 2017 